\title{
Valuasi Ekonomi Objek Wisata Berbasis Jasa Lingkungan Menggunakan Metode Biaya Perjalanan di Pantai Batu Karas Kabupaten Pangandaran
}

\author{
Economic Valuation of Environmental Service-Based Tourism Object in Batu Karas \\ Beach-Pangandaran Using the Travel Cost Method
}

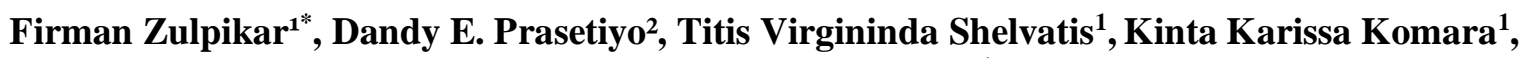
Monica Pramudawardhani ${ }^{1}$

${ }^{1}$ Program Studi Green Economy, Fakultas Ekonomi dan Sosial, Surya University, Jl. Boulevard Gading Serpong kav. M5 No. 21 Summarecon Serpong, Tangerang, Banten 15810; ${ }^{2}$ Program Studi Agribisnis, Fakultas Ekonomi dan Sosial, Surya University, Jl. Boulevard Gading Serpong kav. M5 No. 21 Summarecon Serpong, Tangerang, Banten 15810; *Penulis korespondensi, e-mail: firman.zulfikar@surya.ac.id
\end{abstract} (Diterima: 15 Oktober 2016; Disetujui: 27 Desember 2016)

\begin{abstract}
Batu Karas beach at Pangandaran Regency, West Java Province has the potential of natural beauties that can be used as an ecotourism object. The purpose of this study was to determine the economic value of environmental service-based tourism and to identify factors that contribute to the tourism demand to Batu Karas beach. Individual Travel Cost Method (ITCM) was used to estimate the potential economic value of tourism activity, and linear regression analysis was used to determine the influence factors of tourism demand. Data was obtained through questionnaires to respondents. The results showed that the most influential factors of the level of tourist demand to Batu Karas beach are travel cost, distance and duration in the location. The demand equation model based on travel cost method is $Y=1.766-0.000001887 X_{1}$; where $Y=$ tourism demand and $X_{1}=$ travel cost. Potential economic value of ecotourism in Batu Karas beach reached $R p$ 86,571,960,874.00 annually with a consumer surplus of $R p$ 566,183.00 per individual per year. Major economic benefits from tourism activities in Batu Karas beach brings socio-economic improvement of the local community.
\end{abstract}

Keyword: Batu Karas, economic valution, ecotourism, travel cost.

\begin{abstract}
ABSTRAK
Pantai Batu Karas di Kabupaten Pangandaran memiliki potensi sumber daya alam yang dapat digunakan sebagai objek wisata. Penelitian ini bertujuan menentukan nilai ekonomi wisata berbasis jasa lingkungan dan mengindentifikasi faktor-faktor yang mempengaruhi permintaan pengunjung ke Pantai Baru Karas. Metode Biaya Perjalanan Individu (Individual Travel Cost Method) dipilih untuk mengestimasi potensi ekonomi aktivitas wisata di Pantai Batu Karas, sedangkan faktor-faktor yang mempengaruhi permintaan pengunjung ditentukan dengan analisis regresi linear. Data diperoleh melalui kuesioner kepada para pengunjung. Hasil penelitian menunjukkan variabel biaya perjalanan, jarak tempuh dan durasi kunjungan berpengaruh signifikan terhadap tingkat kunjungan wisatawan ke Pantai Batu Karas. Model permintaan wisata ke Pantai Baru Karas berdasarkan biaya perjalanan yaitu $\mathrm{Y}=1.766-0.000001887 \mathrm{X}_{1}$ ketika $\mathrm{Y}$ adalah tingkat kunjungan dan $\mathrm{X}_{1}$ adalah biaya perjalanan. Potensi ekonomi ekowisata di Pantai Batu Karas mencapai Rp 86,571,960,874.00 per tahun dengan nilai surplus konsumen sebesar Rp 566,183.00
\end{abstract}


per individu per tahun. Keuntungan ekonomi yang besar dari aktivitas wisata di Pantai Batu Karas memiliki pengaruh positif terhadap peningkatan sosial ekonomi masyarakat setempat.

Kata kunci: Batu Karas, biaya perjalanan, valuasi ekonomi, wisata alam.

\section{PENDAHULUAN}

Pantai Batu Karas merupakan salah satu destinasi wisata unggulan yang ada di Kabupaten Pangandaran. Pantai ini berjarak sekitar $34 \mathrm{~km}$ dari Ibukota Kabupaten Pangandaran (Pantai Pangandaran). Daya tarik utama Pantai Batu Karas yaitu karakteristik pantainya yang berpasir halus dan landai sehingga aman untuk aktivitas berenang. Pantai ini juga memiliki gelombang laut yang cocok bagi peselancar pemula serta pemandangan laut luar biasa yang dapat dinikmati dari tebing batu yang menjorok ke arah laut. Potensi sumber daya alam berupa keindahan pantai di Batu Karas telah mengundang banyak wisatawan untuk datang berwisata. Hal ini berpotensi mendatangkan keuntungan ekonomi bagi masyarakat setempat maupun pemerintah daerah.

Keberadaan objek wisata Pantai Batu Karas sangat penting dan strategis bagi Kabupaten Pangandaran. Aktivitas wisata di Pantai Batu Karas dapat mengasilkan Pendapatan Asli Daerah (PAD) bagi Kabupaten Pangandaran serta menjadi sektor pengerak dalam upaya penciptaan lapangan pekerjaan dan pembangunan ekonomi bagi masyarakat sekitar. Mengingat perannya yang sangat penting maka eksistensi wisata Pantai Batu Karas harus ditingkatkan dan dikembangkan agar mendatangkan keuntungan ekonomi yang besar di masa depan.

Keindahan lanskap wilayah pantai Batu Karas yang dimanfaatkan sebagai objek wisata merupakan salah satu jenis jasa lingkungan yang dapat memberikan nilai ekonomi bagi masyarakat sekitar. Nilai ekonomi ini diperoleh melalui skema pembayaran jasa lingkungan oleh siapa saja yang mendapatkan manfaat dari jasa lingkungan tersebut. Menurut Pagiola (2005), dasar teori ekonomi dari pembayaran jasa lingkungan secara konseptual sebenarnya sederhana yaitu beneficiary pays atau penerima manfaat yang membayar. Mekanisme pembayaran jasa lingkungan di Indonesia telah diatur dalam UU No. 32 tahun 2009 mengenai Pengelolaan dan Perlindungan Lingkungan Hidup. Pembayaran jasa lingkungan pada dasarnya merupakan skema yang bertujuan merestorasi dan melindungi ketersediaan barang dan jasa lingkungan yang berkelanjutan serta biaya yang lebih efisien dalam jangka waktu yang lama.

Memahami mengenai nilai dari berbagai jasa lingkungan tersebut sangat penting dalam pengambilan keputusan terkait pengelolaan sumber daya yang menguntungkan dari sisi ekonomi dan berkelanjutan dari sisi lingkungan. Namun demikian, nilai ekonomi sumber daya alam yang menawarkan keindahan alam atau lanskap, pada umumnya bersifat non-market atau tidak dapat diperdagangkan (Jala, 2015; Godari dan Ghiyasi, 2014; Jaafar dan Maideen, 2012). Untuk mengestimasi nilai ekonomi dari jasa lingkungan tersebut harus menggunakan teknik penilaian (valuation) tertentu.

Menurut Jala (2015), salah satu teknik valuasi ekonomi yang dapat digunakan untuk menilai jasa lingkungan berupa keindahan alam yang dimanfaatkan sebagai objek wisata dapat dilakukan dengan metode biaya perjalanan atau Travel Cost Method (TCM). Premis dasar dari metode biaya perjalanan menyatakan bahwa waktu dan biaya perjalanan yang dikeluarkan oleh individu untuk mengunjungi suatu lokasi mewakili harga untuk mengakses tempat tersebut (Jala, 2015; Becker et al., 2005). Metode biaya perjalanan dapat menggunakan dua pendekatan yaitu biaya perjalanan berdasarkan zona wilayah (Zonal Travel Cost Method) dan biaya perjalanan individu (Individual Travel Cost Method). Dalam dua dekade terakhir, Individual Travel Cost Method (ITCM) lebih banyak digunakan mengingat kemajuan teknologi informasi dan kelebihannya 
karena mampu memotret karakteristik sosial ekonomi pengunjung seperti usia, pendapatan, dan pendidikan. Informasi ini sulit diperoleh jika menggunakan metode biaya perjalanan berbasis zona (Blackwell, 2007).

Tujuan dari penelitian ini adalah untuk mengestimasi potensi nilai ekonomi dari objek wisata Pantai Batu Karas menggunakan pendekatan Individual Travel Cost Method serta mengidentifikasi faktor-faktor yang berpengaruh terhadap tingkat kunjungan wisatawan ke Pantai Batu Karas.

\section{METODOLOGI}

\section{Ruang Lingkup Penelitian}

Wilayah kajian dalam penelitian ini yaitu sepanjang Pantai Batu Karas yang digunakan untuk aktivitas wisata dengan total panjang pantai sekitar $1 \mathrm{~km}$. Data jumlah wisatawan yang digunakan dalam penelitian ini yaitu data kunjungan wisatawan domestik pada tahun 2015. Analisis yang dilakukan meliputi analisis deskriptif mengenai karakteristik sosial ekonomi pengunjung dan analisis statistik untuk mengestimasi potensi nilai ekonomi wisata.

\section{Waktu dan Tempat Penelitian}

Penelitian dilakukan di Pantai Batu Karas, Desa Batu Karas, Kecamatan Cijulang, Kabupaten Pangandaran. Pengambilan sampel dilakukan pada bulan Februari tahun 2016 selama 4 hari yang mewakili kunjungan pada hari biasa dan libur akhir pekan.

\section{Teknik Pengambilan Sampel}

Responden dalam penelitian ini adalah wisatawan yang berkunjung ke Pantai Batu Karas. Sampel pengunjung diambil menggunakan metode quoted accidental sampling. Teknik ini dikenakan pada individu yang secara kebetulan dijumpai di lokasi wisata Pantai Batu Karas pada saat melakukan penelitian. Usia responden dibatasi minimum 15 tahun. Penentuan jumlah ukuran sampel mengacu pada rumus Lemeshow (1997):

$$
n=\frac{p(1-p)(Z \alpha / 2)^{2}}{D^{2}}
$$

Dimana:

$\mathrm{n}$ : jumlah sampel yang dibutuhkan

$\mathrm{Z}$ : tingkat kepercayaan $(95 \%)$

$\mathrm{p}$ : maksimum estimasi (0.5)

D: limit dari eror atau presisi absolut $(10 \%)$

Berdasarkan rumus Lemeshow tersebut maka jumlah sampel yang dibutuhkan untuk penelitian ini adalah sebagai berikut:

$$
\begin{aligned}
& n=\frac{p(1-p)(Z \alpha / 2)^{2}}{D^{2}} \\
& =\frac{0.5(1-0.5) \cdot\left(1.96^{2}\right)}{0.1^{2}} \\
& =96 \text { orang }
\end{aligned}
$$

\section{Variabel Penelitian}

Untuk mengetahui tingkat kunjungan wisatawan ke Pantai Batu Karas, maka dilakukan pengukuran dengan pendekatan kuantitatif non experimental menggunakan kuisioner yang memuat variabel-variabel yang diteliti. Penentuan varibel penelitian ini merupakan kombinasi dari variabel-variabel penelitian yang telah dilakukan oleh Tazkia dan Hayati (2012), Blackwell (2007), serta Ward dan Beal (2000) dengan topik penelitian serupa. Adapun variabel penelitian yang diuji dalam penelitian ini meliputi:

Variabel dependent: $\mathrm{Y}$ : Tingkat kunjungan

Variabel independent: $\mathrm{X}_{1}$ : Biaya total perjalanan $\mathrm{X}_{2}$ : Jarak tempuh $(\mathrm{km})$

$\mathrm{X}_{3}$ : Tingkat pendapatan

$\mathrm{X}_{4}$ : Durasi kunjungan

$\mathrm{X}_{5}$ : Tingkat pendidikan

$\mathrm{X}_{6}:$ Usia

$\mathrm{X}_{7}$ : Jumlah anggota

\section{Analisis Data}

Analisis data dalam penelitian ini menggunakan metode deskriptif dan kuantitatif. Metode deskriptif digunakan untuk menggambarkan kondisi umum wilayah kajian dan karakteristik sosial ekonomi pengunjung. Adapun metode kuantitatif dilakukan dengan analisis regresi linear berganda menggunakan 
software SPSS untuk mengetahui hubungan antar variabel yang diteliti. Hubungan tersebut dapat diekspresikan dalam bentuk persamaan yang menghubungkan variabel terikat $\mathrm{Y}$ dengan satu atau lebih variabel bebas $X_{1}, X_{2}, \ldots, X_{n}$. Dalam analisis regresi berganda pola hubungan antar variabel diekspresikan dalam sebuah persamaan regresi yang dapat diformulasikan sebagai berikut:

$$
\begin{aligned}
Y= & f\left(X_{1}, X_{2}, X_{3}, X_{4}, \ldots, X_{n}\right) \\
Y= & \alpha+\beta_{1} X_{1}+\beta_{2} X_{2}+\beta_{3} X_{3}+\beta_{4} X_{4}+\ldots \\
& \beta_{n} X_{n}
\end{aligned}
$$

Dimana :

$$
\begin{aligned}
& \alpha=\text { intercept } \\
& \beta=\text { koefisien } \\
& X=\text { variabel penelitian }
\end{aligned}
$$

\section{Perhitungan Nilai Potensi Ekonomi Wisata}

Nilai potensi ekonomi ditentukan dengan cara menghitung nilai surplus konsumen tiap individu pertahun. Untuk menghitung nilai surplus konsumen, digunakan formulasi sebagai berikut:

$$
\mathrm{Dx}=\mathrm{Qx}=\mathrm{a}-\mathrm{bP}
$$

Persamaan di atas diturunkan dalam bentuk persamaan integral terbatas, dengan batas bawah yaitu biaya terendah yang dibayarkan pengunjung dan batas teratas yaitu biaya tertinggi yang dikeluarkan pengunjung untuk beriwisata ke Pantai Batu Karas, sehingga dapat diformulasikan sebagai berikut:

$$
S K=\int_{p 0}^{p 1} f\left(P_{x}\right) d P
$$

\section{HASIL DAN PEMBAHASAN}

\section{Gambaran Umum Wilayah}

Pantai Batu Karas merupakan salah satu objek wisata yang berada di Kabupaten Pangandaran. Pantai ini terletak sekitar $34 \mathrm{~km}$ dari Pantai Pangandaran. Pada awalnya, Pantai Batu Karas masuk ke dalam wilayah Kabupaten Ciamis, namun setelah terjadi pemekaran wilayah, pantai ini sekarang menjadi bagian dari kabupaten baru yaitu Kabupaten Pangandaran. Akses menuju lokasi wisata dari Kota Bandung dapat ditempuh dengan perjalanan darat menggunakan kendaraan umum atau mobil rental selama kurang lebih enam jam perjalanan.

Infrastruktur penunjang wisata tergolong cukup memadai seperti telah tersedia tempat penginapan, restoran, tempat penyewaan papan selancar, pusat cinderamata, fasilitas parkir yang luas serta toilet umum yang terdapat di berbagai titik. Fasilitas lain yang tersedia yaitu bumi perkemahan dan olah raga air.

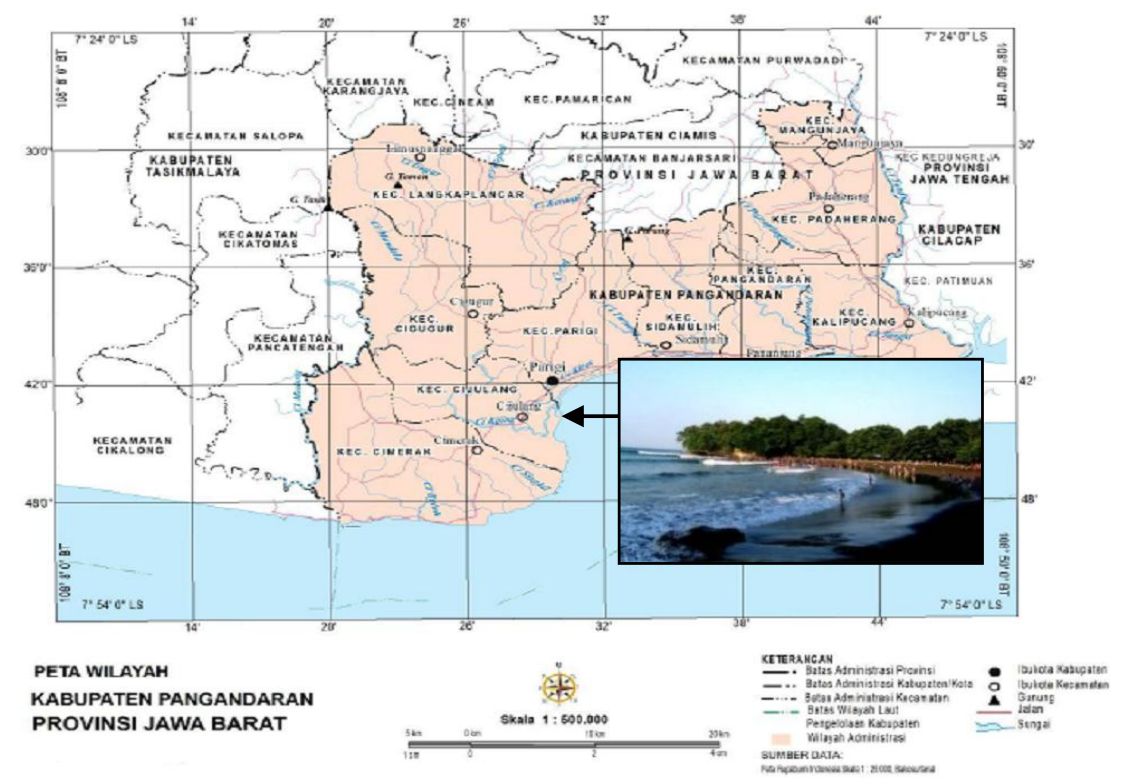

Gambar 1. Peta lokasi Pantai Batu Karas, Kabupaten Pangandaran 


\section{Tingkat Kunjungan Wisatawan}

Jumlah wisatawan yang berkunjung ke Pantai Baru Karas dari tahun ke tahun terus mengalami peningkatan. Pada tahun 2008 jumlah wisatawan yang berkunjung hanya mencapai 46,421 orang, namun pada tahun 2012 jumlahnya melonjak yaitu mencapai 169,406 orang (Dinas Kebudayaan dan Pariwisata Kabupaten Ciamis, 2012). Pada tahun 2015, jumlah kunjungan wisatawan ke Pantai Batu Karas telah mencapai 277,711 orang (Dinas UMKM Kabupaten Pangandaran, 2015).

Peningkatan jumlah pengunjung ke Pantai Batu Karas didorong oleh semakin baiknya infrastruktur jalan menuju lokasi wisata, serta semakin gencarnya promosi kawasan wisata yang berada di sepanjang pantai selatan Kabupaten Pangandaran antara lain Pantai Pangandaran, Green Canyon, Citumang dan Pantai Batu Karas.

Wisatawan yang berkunjung ke Pantai Batu Karas merupakan wisatawan domestik yang mayoritas berasal dari wilayah di sekitar Kabupaten Pangandaran seperti Ciamis, Tasikmalaya, Garut, Bandung dan beberapa daerah di Jawa Tengah. Pada umumnya mereka datang pada musim libur panjang seperti libur hari raya dan tahun baru. Pada musim-musim tertentu Pantai Batu Karas juga sering dikunjungi oleh wisatawan mancanegara. Gambar 2 di bawah ini menunjukkan sebaran responden Pantai Batu Karas berdasarkan asal wilayahnya.

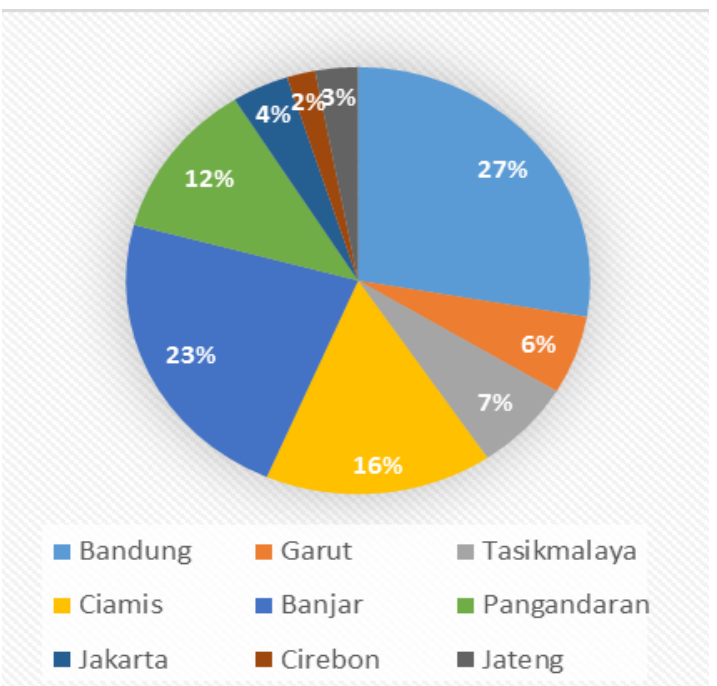

Gambar 2. Sebaran responden berdasarkan asal wilayah. Sumber: Hasil pengolahan data primer.

\section{Karakteristik Sosial Ekonomi Responden}

Karakteristik sosial ekonomi responden menggambarkan profil dari pengunjung yang berwisata ke Pantai Batu Karas. Karakteristik responden yang diamati antara lain jenis pekerjaan, jenis kelamin, usia, tingkat pendidikan, jarak tempuh, tingkat pendapatan namun secara keseluruhan proporsi diantara keduanya relatif seimbang.

Tingkat pendidikan responden dapat menggambarkan mengenai pengetahuan, wawasan serta motivasi seseorang untuk melakukan perjalanan wisata.
Tabel 1. Sebaran responden berdasarkan jenis kelamin

\begin{tabular}{lc}
\hline \multicolumn{1}{c}{ Jenis Kelamin } & Persentase (\%) \\
\hline Laki-laki & 48 \\
Perempuan & $\mathbf{5 2}$ \\
\hline Sumber: Hasil analisis data primer &
\end{tabular}

Sumber: Hasil analisis data primer.

Tabel 2. Tingkat pendidikan responden

\begin{tabular}{lc}
\hline \multicolumn{1}{c}{ Tingkat Pendidikan } & Persentase (\%) \\
\hline SMP & 21 \\
SMA & $\mathbf{5 8}$ \\
S1 & 21 \\
\hline
\end{tabular}

Sumber: Hasil analisis data primer. 
Tabel 2 menunjukkan bahwa mayoritas responden memiliki tingkat pendidikan SMA (58\%). Secara umum tingkat pendidikan responden relatif baik karena sebagian besar telah menyelesaikan pendidikan dasar minimal 12 tahun. Sebanyak $21 \%$ responden memiliki tingkat pendidikan yang lebih baik karena telah berhasil menyelesaikan pendidikan di perguruan tinggi.

Tabel 3. Jarak tempuh menuju lokasi

\begin{tabular}{|c|c|}
\hline Jarak Tempuh (km) & Persentase $(\%)$ \\
\hline $\begin{array}{l}<\mathbf{1 0 0} \\
100-200\end{array}$ & $\begin{array}{l}\mathbf{3 8} \\
30\end{array}$ \\
\hline $201-300$ & 26 \\
\hline$>300$ & 6 \\
\hline
\end{tabular}

Sumber: Hasil analisis data primer.

Tabel 3 menunjukkan bahwa untuk mencapai lokasi wisata di Batu Karas, mayoritas responden harus menempuh jarak yang mencapai $100 \mathrm{~km}$.

Jarak tempuh menuju lokasi wisata berpengaruh terhadap keputusan seseorang untuk mengadakan suatu perjalanan baik berkaitan dengan ketersediaan waktu maupun ketersediaan anggaran. Wisatawan yang datang dari tempat yang lebih jauh, jumlahnya lebih sedikit dari pada wisatawan yang tempat tinggalnya lebih dekat ke lokasi wisata. Menurut Becker et al. (2005), jarak memiliki pengaruh sangat kuat terhadap tingkat kunjungan perkapita dibandingkan dengan variabel sosial ekonomi lainnya.

Tabel 4. Distribusi tingkat pendapatan responden

\begin{tabular}{lc}
\hline \multicolumn{1}{c}{ Pendapatan $(\mathbf{R p})$} & Persentase $(\boldsymbol{\%})$ \\
\hline$<\mathbf{1 , 0 0 0 , 0 0 0}$ & $\mathbf{6 0}$ \\
$1,000,000-3,000,000$ & 33 \\
$>4,000,000$ & 7 \\
\hline
\end{tabular}

Sumber: Hasil analisis data primer.

Tingkat pendapatan pengunjung akan berpengaruh terhadap pertimbangan untuk mengalokasikan anggaran wisata, termasuk untuk transportasi, konsumsi dan akomodasi selama wisata. Pendapatan juga akan mempengaruhi pilihan jenis atau objek wisata yang ingin dikunjungi.

Hasil penelitian ini menunjukkan bahwa hampir sebagian besar responden memiliki tingkat pendapatan yang kurang dari 1 juta rupiah $(60 \%)$. Data ini berbanding lurus dengan data kelas umur dan tingkat pekerjaan yang sebagian besar pegunjung merupakan pelajar yang berusia 15 sampai 20 tahun. Pada usia tersebut, pelajar atau mahasiswa rata-rata belum memiliki penghasilan sendiri, kebutuhan hidup masih dibantu oleh orang tua termasuk alokasi anggaran untuk tujuan wisata. Pengunjung yang berusia produktif dan telah memiliki pekerjaan sendiri jumlahnya relatif kecil, hal ini mengkonfirmasi bahwa pangsa pasar untuk wisata Pantai Batu Karas adalah masyarakat kelas menengah ke bawah.

Tabel 5. Biaya kunjungan responden

\begin{tabular}{lc}
\hline \multicolumn{1}{c}{ Biaya Perjalanan (Rp) } & Persentase $(\boldsymbol{\%})$ \\
\hline$<100,000$ & 7 \\
$\mathbf{1 0 0 , 0 0 0}-\mathbf{2 0 0 , 0 0 0}$ & $\mathbf{6 9}$ \\
$210,000-300,000$ & 9 \\
$310,000-400,000$ & 8 \\
$410,000-500,000$ & 7 \\
\hline
\end{tabular}

Sumber: Hasil analisis data primer.

Tabel 5 menunjukkan besaran biaya yang dikeluarkan oleh pengunjung untuk berwisata ke Pantai Batu Karas. Besaran biaya perjalanan menuju lokasi wisata berpengaruh terhadap keputusan seseorang untuk mengadakan perjalanan wisata ke suatu lokasi. Mayoritas responden $(69 \%)$ mengeluarkan biaya antara Rp 100,000.00 sampai Rp 200,000.00 Hasil perhitungan menunjukkan bahwa rata-rata biaya aktual yang dikeluarkan oleh pengunjung yaitu sebesar Rp 196,782.00 per kunjungan. Komponen biaya pengeluaran pengunjung meliputi biaya transportasi, biaya konsumsi, biaya akomodasi, tiket masuk, biaya souvenir, dan biaya lain-lain yang dikeluarkan dalam satu kali kunjungan ke objek wisata. Distribusi biaya kunjungan ditampilkan pada Gambar 3 di bawah ini. 


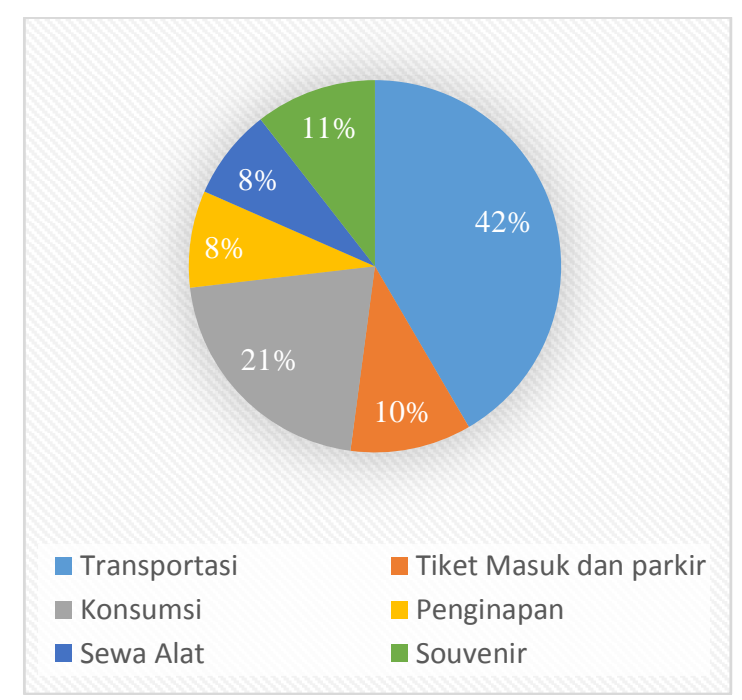

Gambar 3. Distribusi biaya wisata ke Pantai Batu Karas Sumber: Hasil pengolahan data primer.

Berdasarkan distribusi biaya wisata diketahui bahwa biaya untuk transportasi merupakan komponen terbesar yakni mencapai $42 \%$ dari total biaya. Sisanya sebesar $58 \%$ terbagi ke dalam beberapa komponen biaya lainnya. Persentase biaya untuk penginapan tergolong kecil karena pada umumnya pengunjung hanya berwisata selama satu hari dan tidak menginap di Batu Karas karena keterbatasan hotel yang tersedia.

\section{Fungsi Permintaan Wisata}

Sebelum dilakukan uji regresi, terlebih dahulu dilakukan evaluasi ekonometri dengan uji asumsi klasik meliputi uji multikolinearitas, uji heteroskedastisitas, dan uji autokorelasi. Hasil uji mutikolinearitas menunjukkan nilai VIF lebih kecil dari 10 dan tolerance lebih kecil dari 1 untuk semua variabel penelitian. Uji heteroskedastisitas menggunakan bantuan grafis menunjukkan sebaran titik merata di atas dan di bawah nilai 0 . Uji autokorelasi menggunakan Uji Durban Watson menunjukkan nilai DW mendekati nilai 2 . Secara umum hasil pengujian menyatakan tidak terjadi pelanggaran asumsi sehigga layak untuk dilanjutkan ke tahap pengujian berikutnya.
Tabel 6. Hasil uji F

\begin{tabular}{lrrrrr}
\hline \multicolumn{1}{c}{ Model } & $\begin{array}{c}\text { Sum of } \\
\text { Squares }\end{array}$ & df & $\begin{array}{c}\text { Mean } \\
\text { Square }\end{array}$ & F & Sig. \\
\hline Regression & 29.771 & 7 & 4.253 & 7.168 & $.000^{\mathrm{b}}$ \\
Residual & 54.589 & 92 & .593 & & \\
Total & 84.360 & 99 & & & \\
\hline Stal & & & & &
\end{tabular}

Sumber: hasil analisis data primer.

Hasil Uji F pada Tabel 6. menunjukkan bahwa nilai $\mathrm{F}$ hitung yaitu $=7.168$ dan nilai $\mathrm{F}$ tabel $=2.11077$. Nilai $\mathrm{F}$ hitung lebih besar dari F tabel yang berarti bahwa variabel bebas secara bersama-sama memberikan pengaruh terhadap varibel terikat yaitu tingkat kunjungan wisatawan.

Hasil uji $\mathrm{F}$ belum dapat mengetahui secara pasti variabel independent mana yang memiliki pengaruh secara langsung dan signifikan terhadap variabel dependent (tingkat kunjungan). Oleh karena itu dilanjutkan dengan analisis regresi linear berganda untuk mengetahui variabel mana saja yang memberikan pengaruh nyata terhadap variabel terikat.

Hasil analisis regresi linear berganda disajikan pada Tabel 7. Nilai koefisien determinasi $\mathrm{R}^{2}$ yaitu sebesar 0.35 yang berarti variabel bebas hanya mampu menjelaskan variasi perubahan pada variabel terikat sebesar $35 \%$, sisanya dijelaskan oleh variabel lain yang tidak diteliti dalam penelitian ini. 
Tabel 7. Hasil regresi linear berganda

\begin{tabular}{lcccc}
\hline \multicolumn{1}{c}{ Variabel } & Koef. & $\begin{array}{c}\text { Std. } \\
\text { Error }\end{array}$ & $\mathbf{t}$ & Sig. \\
\hline Intercept & 1.766 & .570 & 3.098 & $.003^{*}$ \\
Biaya & $-1.88 \mathrm{E}-$ & .000 & -2.189 & $.031^{*}$ \\
Perjalanan & 6 & & & \\
Jarak & -.006 & .001 & -5.262 & $.000^{*}$ \\
Pendapatan & $6.77 \mathrm{E}-8$ & .000 & 1.781 & .078 \\
Durasi & 1.433 & .418 & 3.430 & $001^{*}$ \\
Tingkat & -.021 & .037 & -.548 & .585 \\
Pendidikan & -.002 & .011 & -.220 & .826 \\
Usia & -.084 & .059 & -1.421 & .159 \\
Jumlah & .304 & & \\
Anggota & .353 & & \\
\hline R Adjusted & .32 & & \\
$\mathrm{R}^{2}$ & *) signifikan pada $\alpha=0.05$ & & \\
Sumber: Hasil Analisis data primer. &
\end{tabular}

Berdasarkan tabel tersebut diperoleh persamaan regresi sebagai berikut:

$\mathrm{Y}=1.766-0.000001887 \mathrm{X}_{1}-0.006 \mathrm{X}_{2}+$ $0.00000006771 \mathrm{X}_{3}+1.433 \mathrm{X}_{4}-0.021 \mathrm{X}_{5}-0.002$ $\mathrm{X}_{6}-0.084 \mathrm{X}_{7}$

Hasil pengujian menunjukkan bahwa dari tujuh variabel sosial ekonomi yang diamati dalam penelitian ini, terdapat tiga variabel yang berpengaruh signifikan $(\alpha=0.05)$ terhadap tingkat kunjungan wisatawan ke Pantai Batu Karas. Ketiga variabel tersebut yaitu biaya perjalanan, jarak dan durasi kunjungan. Variabel biaya perjalanan dan jarak tempuh bertanda negatif, menunjukkan bahwa apabila biaya perjalanan semakin murah dan jarak tempuh semakin dekat, maka jumlah kunjungan akan semakin meningkat. Jarak merupakan sesuatu yang sangat berpengaruh terhadap pemilihan tempat wisata (Becker et al., 2005). Hal itu disebabkan oleh karena pengunjung lebih menyukai tempat wisata yang lebih dekat dengan tempat tinggal mereka. Variabel durasi kunjungan bertanda positif menunjukkan bahwa semakin lama durasi kunjungan maka tingkat kunjungan akan bertambah. Hal ini dapat diasumsikan bahwa pengunjung akan mendapatkan kepuasan lebih jika menambah waktu kunjungan sehingga tertarik untuk datang kembali.

Empat variabel lainnya yaitu pendapatan, pendidikan, usia dan jumlah anggota kelompok tidak berpengaruh signifikan $(\alpha=0.05)$ terhadap tingkat kunjungan wisatawan. Pola wisatawan yang berkunjung ke Pantai Batu Karas pada umumnya melakukan perjalanan berwisata secara massal pada akhir pekan dan hari libur nasional terutama libur lebaran dan tahun baru. Pada periode tersebut sebagian besar masyarakat akan merencanakan perjalanan ke tempat-tempat wisata terdekat sehingga faktor usia, pendidikan, pendapatan dan jumlah kelompok cenderung tidak menjadi bahan pertimbangan oleh wisatawan.

Model permintaan wisata yang diperoleh melalui analisis regresi dapat digunakan untuk membuat kurva permintaan pengunjung melalui proses inversi dari persamaan tingkat kunjungan terhadap biaya perjalanan yaitu $\mathrm{Y}=$ $1.766-0.000001887 \mathrm{X}_{1}$ sehingga diperoleh kurva sebagai berikut:

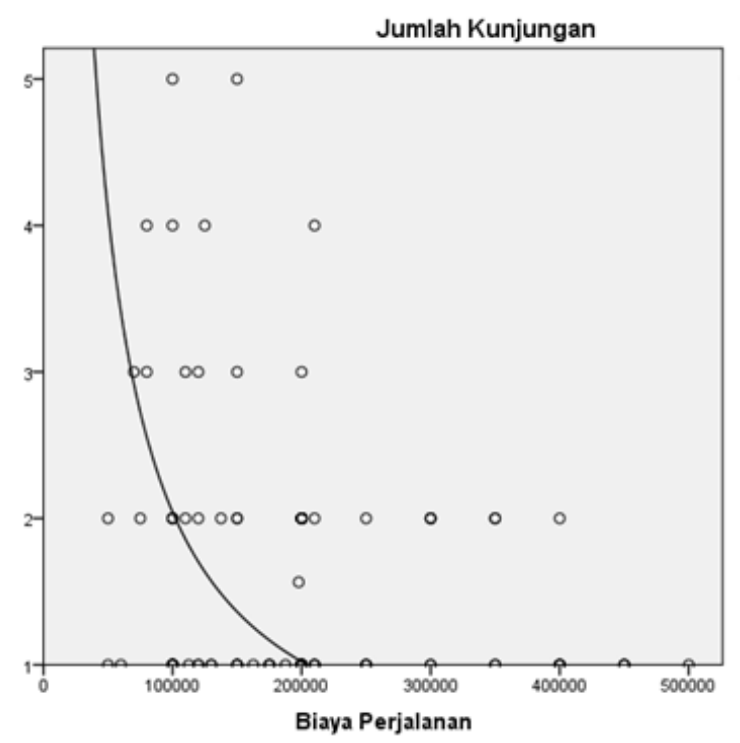

Gambar 4. Kurva permintaan wisata ke Pantai Batu Karas

Sumber: Hasil pengolahan data primer.

Berdasarkan kurva di atas diketahui bahwa jumlah kunjungan akan meningkat apabila biaya kunjungan semakin murah, sebaliknya jumlah wisatawan akan menurun jika biaya kunjungan semakin mahal. Informasi ini dapat digunakan dalam pengembangan objek wisata Pantai Batu Karas ke depan terutama terkait dengan kebijakan penetapan harga-harga dan pangsa pasar wisata. 


\section{Nilai Ekonomi Wisata Pantai Batu Karas}

Model permintaan wisata yang telah diperoleh melalui analisis regresi digunakan untuk menghitung surplus konsumen. Nilai surplus konsumen diperoleh melalui perhitungan integral dengan batas bawah yaitu biaya terendah yang dibayarkan pengunjung dan batas atas merupakan biaya tertinggi yang dikeluarkan pengunjung untuk berwisata ke Pantai Batu Karas. Berdasarkan hasil survei diketahui bahwa biaya terendah yaitu $\mathrm{Rp}$ $50,000.00$ dan biaya tertinggi yaitu $\mathrm{Rp}$ $500,000.00$ sehigga diperoleh rumus integral sebagai berikut:

$$
\mathrm{SK}=\int_{50,000}^{500,000} 1.766-0.000001887 x d x
$$

Hasil perhitungan integral diketahui bahwa nilai surplus konsumen yaitu sebesar Rp 566,183.00 per individu per tahun. Rata-rata tingkat kunjungan wisatawan dalam satu tahun terakhir (12 bulan) diketahui yaitu sebanyak 1.58 kali, dengan demikian nilai surplus konsumen menjadi sebesar Rp 311,734.00 per individu per kunjungan. Nilai ini lebih tinggi dari biaya aktual rata-rata yang dikeluarkan pengunjung yaitu hanya sebesar Rp 196,782.00 per individu per kunjungan. Jika kedua nilai tersebut dibandingkan, maka dapat disimpulkan bahwa pengunjung mendapatkan manfaat jasa lingkungan yang lebih besar daripada biaya yang dikeluarkan. Becker et al. (2005) menyatakan bahwa biaya yang dikeluarkan individu dalam mengunjungi suatu lokasi wisata mencerminkan batas bawah kesediaan seseorang untuk datang ke suatu lokasi wisata.

Potensi nilai ekonomi wisata dapat diketahui dengan cara mengalikan nilai surplus konsumen dengan jumlah wisatawan yang berkunjung pada periode tertentu. Diketahui bahwa jumlah wisatawan yang berkunjung ke Pantai Batu Karas pada tahun 2015 tercatat sebanyak 277,711 orang. Dengan demikian maka nilai potensi ekonomi wisata Pantai Batu Karas pada tahun 2015 diketahui mencapai Rp 86,571,960,874.00. Dengan menggunakan rumus perhitungan yang sama diperoleh nilai ekonomi aktual wisata yaitu sebesar Rp $54,648,575,495.00$ pertahun atau setara dengan $63 \%$ dari total potensi nilai ekonomi yang ada.

Keberadaan objek wisata Pantai Batu Karas memiliki dampak positif terhadap peningkatan ekonomi masyarakat setempat. Banyak masyarakat yang mendapatkan penghasilan baik langsung maupun tidak langsung dari sektor pariwisata. Masyarakat banyak yang bekerja sebagai tukang sewa perahu, sewa peralatan renang, jasa sewa toilet, serta sewa penginapan. Sektor Usaha Mikro Kecil dan Menengah (UMKM) terutama kerajinan tangan, souvenir dan makanan juga tumbuh dengan baik. Pariwisata merupakan sektor ekonomi yang mampu memberikan kontribusi yang signifikan terhadap pertumbuhan ekonomi suatu daerah dan pasar tenaga kerja, serta menciptakan peluang pekerjaan baik langsung dan tidak langsung melalui penyediaan barang dan jasa yang diperlukan untuk kegiatan wisata (Zaei dan Zaei, 2013).

Pembenahan dan perbaikan fasilitas oleh pemerintah setempat perlu ditingkatkan untuk menunjang kenyamanan wisatawan. Peningkatan jumlah kunjungan dapat memberikan dampak positif dalam menyumbang pendapatan daerah (PAD) Kabupaten Pangandaran, serta mendorong pertumbuhan ekonomi masyarakat di sekitar objek wisata.

Hasil penelitian ini dapat dijadikan sebagai bahan dalam pengambilan kebijakan alternatif bagi pemerintah daerah terkait pengembangan objek wisata di Pantai Batu Karas. Bagi para investor hasil penelitian ini dapat menjadi bahan informasi untuk peluang berinvestasi pada sektor pariwisata yang saat ini sedang gencar dipromosikan oleh pemerintah.

\section{KESIMPULAN DAN REKOMENDASI}

\section{Kesimpulan}

Kesimpulan yang dapat diambil dari hasil penelitian ini adalah sebagai berikut: 
Potensi nilai ekonomi wisata Pantai Batu Karas mencapai $\mathrm{Rp} 86,571,960,874.00$ per tahun dengan tingkat pemanfaatan aktual saat ini yaitu sebesar $\mathrm{Rp} 54,648,575,495.00$ per tahun $(63 \%$ dari total potensi ekonomi yang ada).

Biaya perjalanan, jarak dan durasi kunjungan berpengaruh signifikan terhadap tingkat kunjungan wisata ke Pantai Batu Karas, sedangkan usia pengunjung, pendapatan, tingkat pendidikan dan jumlah anggota kelompok tidak berpengaruh signifikan terhadap tingkat kunjungan.

\section{Rekomendasi}

Beberapa rekomendasi yang dapat diberikan berdasarkan hasil penelitian ini antara lain:

Pantai Batu Karas perlu dipromosikan secara optimal sebagai tujuan wisata karena memiliki potensi nilai ekonomi yang tinggi dan sampai saat ini baru termanfaatkan sekitar 63\% dari total potensi ekonomi yang ada.

Eksistensi sumber daya alam pantai yang terdapat di Batu Karas perlu mendapat perhatian, pemeliharaan dan pengelolaan yang baik. Strategi yang dapat dilakukan untuk meningkatkan jumlah wisatawan antara lain melalui peningkatan akses transportasi umum dan jalan raya menuju lokasi wisata agar biaya perjalanan turun serta membangun fasilitas pendukung lain seperti homestay agar durasi kunjungan wisatawan semakin lama.

\section{Ucapan Terima Kasih}

Penelitian ini didanai oleh Lembaga Penelitian dan Pengabdian Masyarakat (LPPM) Surya University dan Surya Center for Community Development (SCCD). Kami mengucapkan terima kasih kepada seluruh peneliti SCCD yang telah membantu proses penelitian ini sampai selesai.

\section{DAFTAR PUSTAKA}

Becker, N., Inbar, M., Bahat, O., Choresh, Y., BenNoon, G., \& Yaffe, O. (2005). Estimating the Economic Value of Viewing Griffon Vultures Gyps fulvus: a Travel Cost Model Study at Gamla Nature Reserve, Israel. Oryx, 39 (4), 429-434.

Blackwell, B. (2007). The Value of a Recreational Beach Visit: An Application to Mooloolaba Beach and Comparisons with Other Outdoor Recreation Sites. Economic Analysis \& Policy, 37 (1), 77-98, 2007.

Brandã, C. N., Barbieri, J. C., \& Junior, E. R. (2014). Analysis of the Social, Cultural, Economic and Environmental Impacts of Indigenous Tourism: A Multi-Case Study of Indigenous Communities in the Brazilian Amazon. Sustainable Tourism, 187, 175-185.

Dinas Kebudayaan dan Pariwisata Kabupaten Ciamis. (2012). Tingkat Kunjungan Wisatawan ke Objek Wisata Unggulan di Kabupaten Pangandaran. Dinas Kebudayaan dan Pariwisata Kabupaten Ciamis.

Dinas UMKM Kabupaten Pangadaran. (2015). Data Kunjungan Wisata dan Arus Kendaraan. Disparperindagkop \& UMKM. Kabupaten Pangadaran.

Ekonomou, G., Neofitou, C., \& Matsiori, S. (2013). Applying the Travel Cost Approach for Valuing Recreation Benefits of Fthiotida Coastal Zone. Journal of Environmental Science and Engineering, 2, 389-397.

Ghozali, I. (2005). Analisis Multivariat Dengan Menggunakan SPSS. Semarang: Badan Penerbit Universitas Diponegoro.

Godari, A., \& Ghiyasi, S. (2014). Economic Evaluation of Delfard Region by Travel Cost Method. J. Appl. Environ. Biol. Sci., 4 (3), 273-277.

Hakim, A. R. (2011). Economic Valuation of Nature-Based Tourism Object in Rawapening, Indonesia: An Application of Travel Cost and Contingent Valuation Method. Journal of Sustainable Development, 4 (2), 91-101.

Himayatullah. (2003). Economic Valuation of the Environment and the Travel Cost Approach: The Case of Ayubia Natioanl Park. The Pakistan Development Review, 42 (4), 537551. 
Honey, M. (2008). Ecotourism and Sustainable Development: Who Owns Paradise?, Washington, DC: Island Press.

Jaafar, M., \& Maideen, S. A. (2012). EcotourismRelated Products and Activities, and the Economic Sustainability of Small and Medium Island Chalets. Tourism Management, 33, 683-691.

Jala \& Nandagiri, L. (2015). Evaluation of Economic Value of Pilikula Lake Using Travel Cost and Contingent Valuation Methods. Aquatic Procedia, 4, 1315-1321.

Khan, H. (2004). Demand for Eco-tourism: Estimating Recreational Benefits from the Margalla Hills National Park in Northern Pakistan. Working paper. PeshawarPakistan: Institute of Development Studies (IDS).

Kiper, T., Özdemir, G., \& Saglam, C. (2011). Enviromental, Socio-Cultural and Economical Effects of Ecotourism Perceived by the Local People in the Northwestern Turkey: Kiyiköy Case. Scientific Research and Essays, 6 (19), 4009-4020.

Lemeshow, S., \& Hosmer, D. W. (1997). Applied Survival Analysis Regression Modeling of Time to Event Data. New York: John Wiley and Sons, Inc.

Limaei, S.M., Ghesmati, H., Rashidi, R., \& Yamini, N. (2014). Economic Evaluation of Natural Forest Park Using the Travel Cost Method (Case Study: Masouleh Forest Park, North of Iran)", Journal of Forest Science, 60 (6), 254-261,.

Mateka, J.A., Indrayani, E., \& Harahap, N. (2013). Objek Wisata Pantai Balekambang Kabupaten Malang Jawa Timur. Api Student Journal, 1 (1), 12-22.

Menkhaus, S., \& Lober, D. J. (1996). International Ecotourism and the Valuation of Tropical Rainforests in Costa Rica. Journal of Environmental Management, 47, 1-10.

Pagiola, S. (2005). Assessing the efficiency of payments for environmental services programs: A framework for analysis. Washington: World Bank.

Pascoe, S., Doshi, A., Thébaud, O, \& Thomas, C. R. (2014). Estimating The Potential Impact of Entry Fees for Marine Parks on Dive Tourism in South East Asia. Marine Policy, 47, 147-152.
Premono, B. P., \& Kunarso, A. (2010). Valuasi Ekonomi Taman Wisata Alam Punti Kayu Palembang. Jurnal Penelitian Hutan dan Konservasi Alam, 7 (1), 13-23.

Purwanto. (2013). Valuasi Ekonomi Ekowisata dengan Model Travel Cost dan Dampaknya Terhadap Usaha Kecil Pariwisata. Jurnal Manajemen dan Kewirausahaan, 15 (1), 89102.

Ramdas, M., \& Mohamed, B. (2014). Impacts of Tourism on Environmental Attributes, Environmental Literacy and Willingness to Pay: A Conceptual and Theoretical Review. Procedia - Social and Behavioral Sciences, 144, 378-391.

Sari, D. K. (2011). Pengembangan Pariwisata Objek Wisata Pantai Sigandu Kabupaten Batang. Skripsi. Universitas Diponegoro.

Seenprachawong U. (2003). Economic Valuation of Coral Reefs at Phi Phi Islands, Thailand. Int.

J. Global Environmental Issues, 3 (1), 104114.

Shrestha, R. K., Stein, T. V., \& Clark, J. Valuing Nature-Based Recreation in Public Natural Areas of the Apalachicola River Region, Florida. in press.

Tazkia, F. O., \& Hayati, B. (2012). Analisis Permintaan Objek Wisata Pemandian Air Panas Kalianget, Kabupaten Wonosobo Dengan Pendekatan Travel Cost. Diponegoro Journal of Economics, 1 (1), 1-10.

Ward, F.A., \& Beal, D. (200). Valuing Nature with Travel Cost Models: A Manual. Cheltenham, UK: Edward Elgar.

Yulianto, Fahrudin \& Kusmaningsih. (2007). Analisis Permintaan Rekreasi dan Strategi Pengembangan Wisata Bahari di Gili Trawangan Kabupaten Lombok Barat Provinsi Nusa Tenggara Barat. Buletin Ekonomi Perikanan, 7 (2).

Zaei, M.E. (2013). The Impacts of Tourism Industry on Host Community", European Journal of Tourism Hospitality and Research, 1 (2), 1221. 